\title{
Anionic Polymerization and Block Copolymerization of $N, N$-Diethylacrylamide in the Presence of Triethylaluminium. Kinetic Investigation Using In-line FT-NIR Spectroscopy
}

\author{
by Xavier André, Khaled Benmohamed, Alexander V. Yakimansky, \\ Galina I. Litvinenko, and Axel H. E. Müller*
}

Table S-1. Polymerization of tert-butyl acrylate $(t \mathrm{BA})$ and tert-butyl methacrylate, $(t \mathrm{BMA})$ using 1,1-diphenylhexyllithium (DPHLi) in the presence of $\mathrm{LiCl}$ as initiator in $\mathrm{THF}^{\mathrm{a}}$

\begin{tabular}{cccccccccc}
\hline $\begin{array}{c}\text { Monomer } \\
\text { Run }\end{array}$ & $\begin{array}{c}\mathbf{T} \\
{ }^{\mathrm{C}} \mathrm{C}\end{array}$ & $\begin{array}{c}{[\mathbf{D P H L i}]_{\mathbf{0}}} \\
\mathrm{mmol} \cdot \mathrm{L}^{-1}\end{array}$ & $\begin{array}{c}{[\mathbf{t B}(\mathbf{M}) \mathrm{A}]_{\mathbf{0}}} \\
\mathrm{mmol} \cdot \mathrm{L}^{-1}\end{array}$ & $\begin{array}{c}\mathbf{T i m e}^{\mathrm{b}} \\
\mathrm{min}\end{array}$ & $\begin{array}{c}\mathbf{1 0}^{3} \cdot \\
\mathbf{M}_{\mathbf{n}, \text { theo }}{ }^{\mathrm{c}}\end{array}$ & $\begin{array}{c}\mathbf{1 0}^{3} \cdot \mathbf{M}_{\mathbf{n}, \exp }{ }^{\mathrm{d}} \\
\text { SEC }\end{array}$ & $\begin{array}{c}\mathbf{M}_{\mathbf{w}} / \mathbf{M}_{\mathbf{n}}{ }^{\mathrm{d}} \\
\text { SEC }\end{array}$ & $\begin{array}{c}\mathbf{1 0}^{3} \mathbf{M}_{\mathbf{n}, \mathbf{e x p}}{ }^{\mathrm{e}} \\
\text { MALDI }\end{array}$ & $\boldsymbol{f}^{\mathrm{f}}$ \\
$t$ BA-G & -78 & 1.77 & 88.1 & 1.2 & 6.6 & 10.0 & 1.10 & 6.0 & 1.10 \\
$t$ BA-H & -78 & 2.35 & 94.0 & 1.3 & 5.4 & 6.4 & 1.18 & 4.0 & 1.35 \\
$t$ BA-I & -78 & 0.56 & 23.0 & 1.0 & 5.5 & 7.8 & 1.10 & 5.6 & 0.98 \\
$t$ BMA-J & -30 & 1.74 & 86.4 & 13.8 & 7.3 & 6.9 & 1.04 & 7.9 & 0.93 \\
$t$ BMA-K & -30 & 1.74 & 86.5 & 16.3 & 7.3 & 6.5 & 1.05 & 7.5 & 0.98 \\
$t$ BMA-L & -30 & 1.75 & 87.0 & 12.9 & 7.3 & 7.6 & 1.05 & 8.5 & 0.86 \\
\hline BMA-M & -30 & 1.75 & 87.1 & 19.5 & 7.3 & 8.5 & 1.04 & 9.3 & 0.79 \\
\hline
\end{tabular}

${ }^{\mathrm{a}}[\mathrm{LiCl}] /[\mathrm{DPHLi}]_{0}=7.1-15.9{ }^{\mathrm{b}}$ Time at complete monomer conversion, $\mathrm{X}_{\mathrm{p}}=1{ }^{\mathrm{c}} \mathrm{M}_{\mathrm{n} \text {,theo }}=$ $X_{p} \cdot \mathrm{M}_{t \mathrm{~B}(\mathrm{M}) \mathrm{A}} \cdot[t \mathrm{~B}(\mathrm{M}) \mathrm{A}]_{0} /[\mathrm{DPHLi}]_{0}+\mathrm{M}_{\text {initiator }}{ }^{\mathrm{d}} \mathrm{P} t \mathrm{BMA}$ calibration in THF at $+40{ }^{\circ} \mathrm{C} .{ }^{\mathrm{e}}$ linear mode. ${ }^{\mathrm{f}}$ Initiator efficiency, $f=\mathrm{M}_{\mathrm{n}, \text { theo }} / \mathrm{M}_{\mathrm{n}, \mathrm{MALDI}}$. 


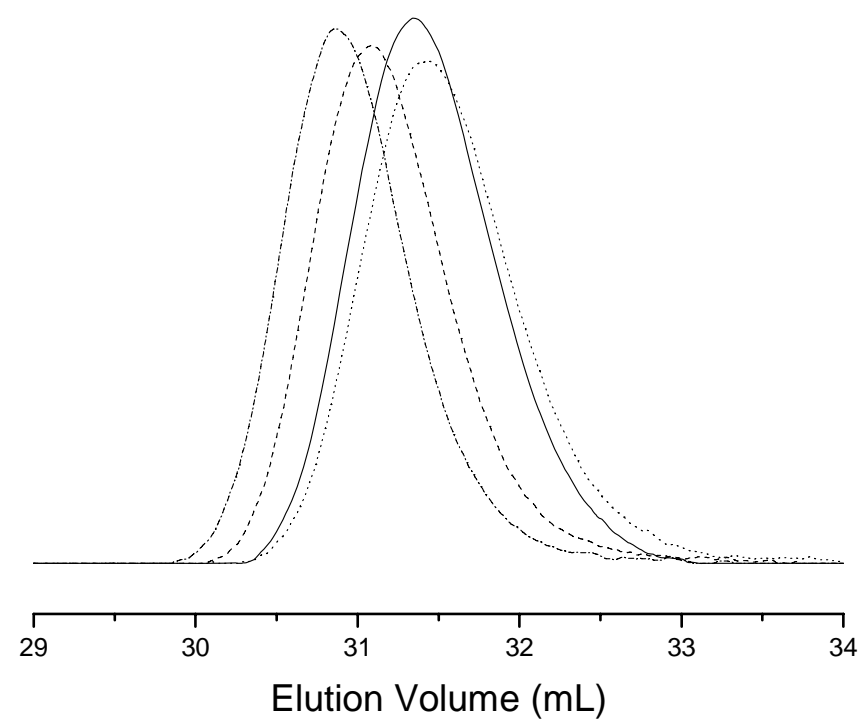

Figure S-1. SEC traces of the PtBMA precursors obtained via the anionic polymerization of $t$ BMA with DPHLi/ $\mathrm{LiCl}$ at $-30{ }^{\circ} \mathrm{C}$ in THF: run $\mathrm{J}(-)$, run $\mathrm{K}(\cdots)$, run $\mathrm{L}\left({ }^{--}\right)$, run $\mathrm{M}\left({ }^{--}\right)$. Reaction conditions: $[\mathrm{DPHLi}]_{0}=0.5-1.8 \mathrm{mmol} \cdot \mathrm{L}^{-1},[t \mathrm{BMA}]_{0}=25.6-87.1 \mathrm{mmol} \cdot \mathrm{L}^{-1}$, $[\mathrm{LiCl}] /[\mathrm{DPHLi}]_{0}=10.5$.

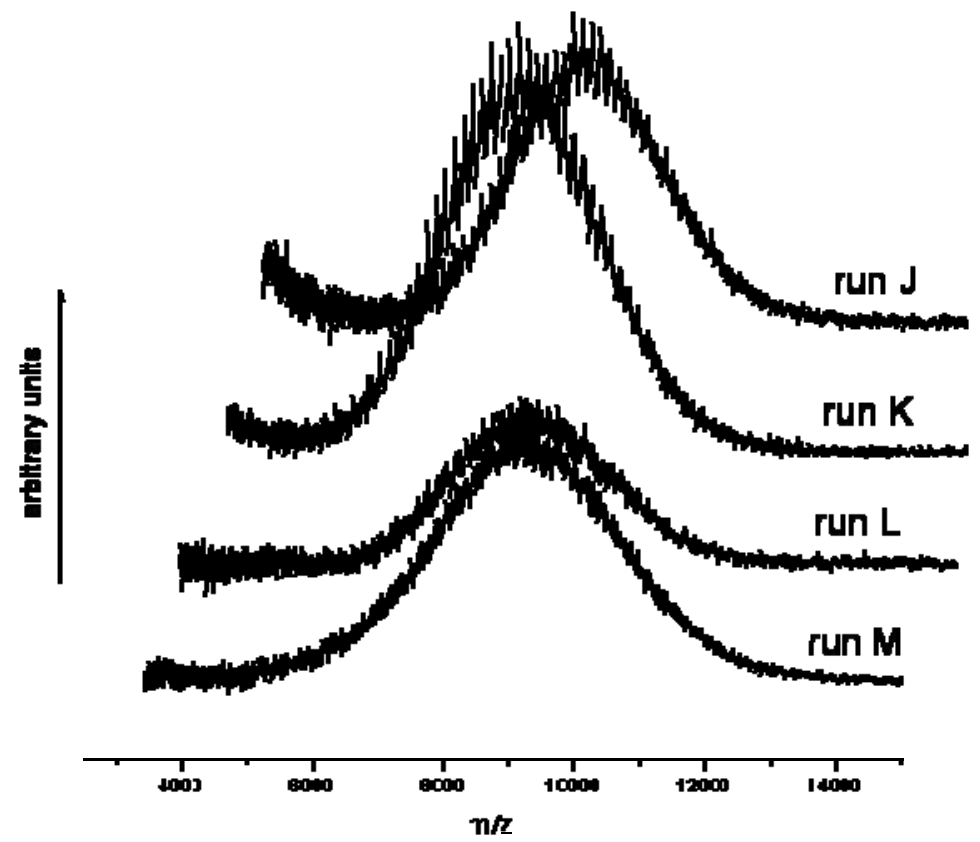

Figure S-2. MALDI-ToF mass spectra of the PtBMA precursors obtained via the anionic polymerization of $t \mathrm{BMA}$ with $\mathrm{DPHLi} / \mathrm{LiCl}$ at $-30{ }^{\circ} \mathrm{C}$ in THF (see Table 1). Reaction conditions: $[\mathrm{DPHLi}]_{0}=0.5-1.8 \mathrm{mmol} \cdot \mathrm{L}^{-1},[t \mathrm{BMA}]_{0}=25.6-87.1 \mathrm{mmol} \cdot \mathrm{L}^{-1},[\mathrm{LiCl}]_{0} /[\mathrm{DPHLi}]_{0}$ $=10.5$. 


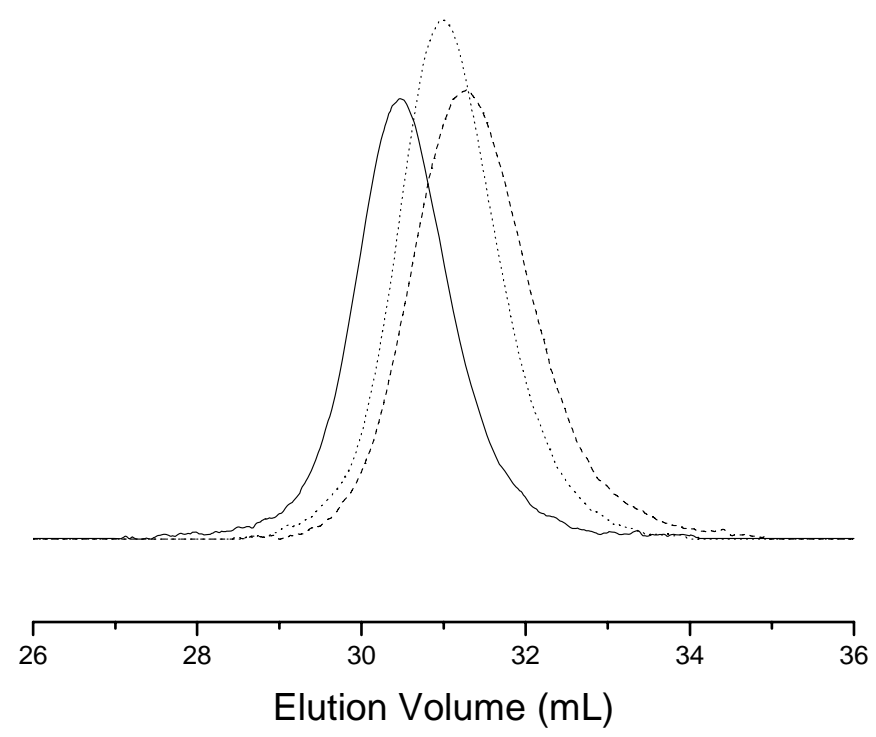

Figure S-3. SEC traces of the PtBA precursors obtained via the anionic polymerization of $t$ BA with DPHLi/ $\mathrm{LiCl}$ at $-78{ }^{\circ} \mathrm{C}$ in THF: run $\mathrm{G}(-), \mathrm{H}(---)$, and I ( $\left.\cdots\right)$. Reaction conditions: $[\mathrm{DPHLi}]_{0}=0.6-2.4 \mathrm{mmol} \cdot \mathrm{L}^{-1},[t \mathrm{BA}]_{0}=23.0-94.0 \mathrm{mmol} \cdot \mathrm{L}^{-1},[\mathrm{LiCl}]_{0} /[\mathrm{DPHLi}]_{0}=7.4-15.9$.

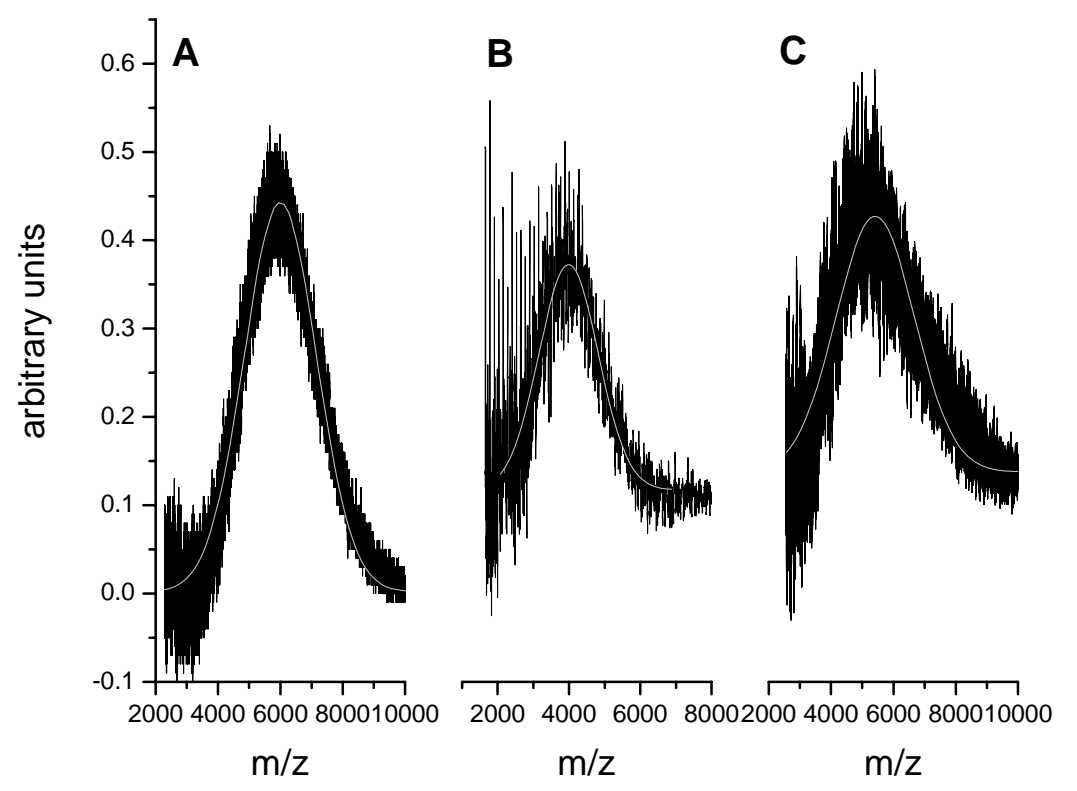

Figure S-4. MALDI-ToF mass spectra of the PtBA precursors obtained via the anionic polymerization of $t \mathrm{BA}$ with $\mathrm{DPHLi} / \mathrm{LiCl}$ at $-78{ }^{\circ} \mathrm{C}$ in THF: run $\mathrm{G}, \mathrm{H}$, and I. Reaction conditions: $[\mathrm{DPHLi}]_{0}=0.6-2.4 \mathrm{mmol} \cdot \mathrm{L}^{-1},[t \mathrm{BA}]_{0}=23.0-94.0 \mathrm{mmol} \cdot \mathrm{L}^{-1},[\mathrm{LiCl}]_{0} /[\mathrm{DPHLi}]_{0}=$ 7.4-15.9. The solid grey lines represent a Gaussian fit of the data points. 
Table S-2. Anionic Polymerization of DEAAm initiated by diphenylhexyllithium (DPHLi) in the presence of $\mathrm{Et}_{3} \mathrm{Al}$ in $\mathrm{THF}$ at $-78^{\circ} \mathrm{C}^{\mathrm{a}, \mathrm{b}}$

\begin{tabular}{cccccc}
\hline run & $\begin{array}{c}\mathbf{M}_{\mathbf{n} \text {,theo }} \\
\mathrm{c}\end{array}$ & $\begin{array}{c}\mathbf{M}_{\mathbf{n}, \mathbf{S E C}} \\
\mathrm{d}\end{array}$ & $\mathbf{M}_{\mathbf{w}} / \mathbf{M}_{\mathbf{n}}{ }^{\mathrm{d}}$ & $\begin{array}{c}\mathbf{M}_{\mathbf{n}, \text { MALDI }} \\
\mathrm{e}\end{array}$ & $\boldsymbol{f}^{\mathrm{f}}$ \\
\hline $\mathrm{N}$ & 9200 & 8790 & 1.19 & 12000 & 0.77 \\
$\mathrm{O}$ & 10000 & 9030 & 1.19 & 11800 & 0.85 \\
$\mathrm{P}$ & 9500 & 10180 & 1.15 & 14700 & 0.65 \\
$\mathrm{Q}^{\mathrm{g}}$ & $4800^{\mathrm{h}}$ & $45400^{\mathrm{i}}$ & 2.34 & - & - \\
$\mathrm{R}^{\mathrm{g}}$ & $4500^{\mathrm{j}}$ & $67800^{\mathrm{i}}$ & 1.71 & - & -
\end{tabular}

${ }^{\text {a }}$ Complete monomer conversion in all cases, $X_{p}=1 .{ }^{\mathrm{b}}[\mathrm{DPHLi}]_{0}=1.80-2.06 \mathrm{mmol} \cdot \mathrm{L}^{-1}$, $[\text { DEAAm }]_{0}=140-150 \mathrm{mmol} \cdot \mathrm{L}^{-1}, \quad\left[\mathrm{Et}_{3} \mathrm{Al}\right] /[\mathrm{DPHLi}]_{0}=6.20-12.8,{ }^{\mathrm{c}} \quad \mathrm{M}_{\mathrm{n} \text {,theo }}=$ $\mathrm{M}_{\text {DEAAm }} \cdot X_{p} \cdot[\mathrm{DEAAm}]_{0} /[\text { Initiator }]_{0}+\mathrm{MW}_{\text {initiator }}{ }^{\mathrm{d}} \mathrm{SEC}$ in NMP $+\mathrm{LiBr}\left(\mathrm{T}=70{ }^{\circ} \mathrm{C}\right)$ as eluent and calibrated with linear PS standards. ${ }^{\mathrm{e}}$ Linear mode. ${ }^{\mathrm{f}}$ Initiator efficiency, $f=\mathrm{M}_{\mathrm{n}, \text { theo }} / \mathrm{M}_{\mathrm{n}, \mathrm{MALDI}}{ }^{\mathrm{g}}$ At $0{ }^{\circ} \mathrm{C} .{ }^{\mathrm{h}} X_{p}=0.98 .{ }^{\mathrm{i}} \mathrm{SEC}$ in THF +0.25 wt. $-\%$ tetrabutylammonium bromide as eluent and calibrated with linear PS standards. ${ }^{\mathrm{j}} X_{p}=0.88$.

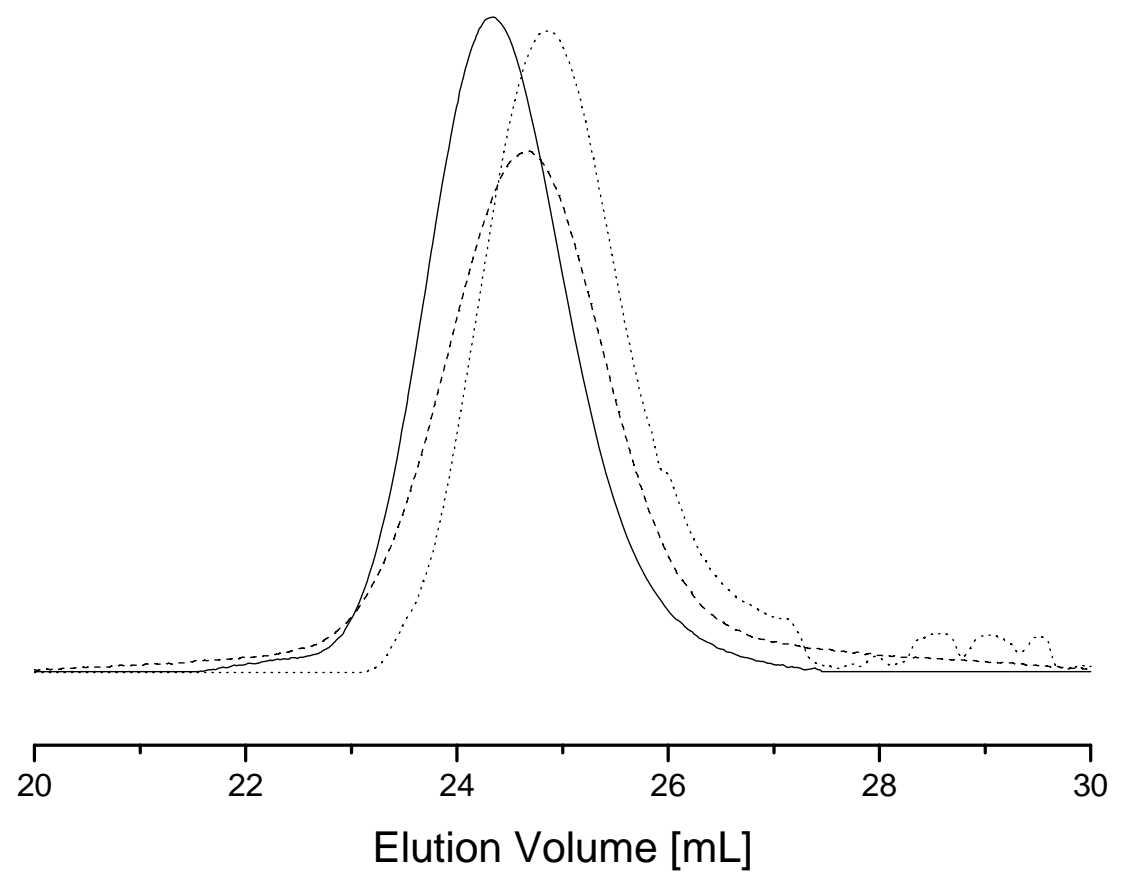

Figure S-5. SEC traces of the PDEAAm synthesized by DPHLi/Et $3 \mathrm{Al}$ in THF at $-78{ }^{\circ} \mathrm{C}$. (---) Run $\mathrm{N},(-)$ run $\mathrm{P}$, and $(\ldots)$ run $\mathrm{O}$ measured in $\mathrm{NMP}+\mathrm{LiBr}$ at $70^{\circ} \mathrm{C}$. Experimental conditions: $[\text { DEAAm }]_{0}=144-150 \mathrm{mmol} \cdot \mathrm{L}^{-1},[\mathrm{DPHLi}]_{0}=2.0-2.1 \mathrm{mmol} \cdot \mathrm{L}^{-1},\left[\mathrm{Et}_{3} \mathrm{Al}\right]=13.0-26.9 \mathrm{mmol} \cdot \mathrm{L}^{-1}$. 

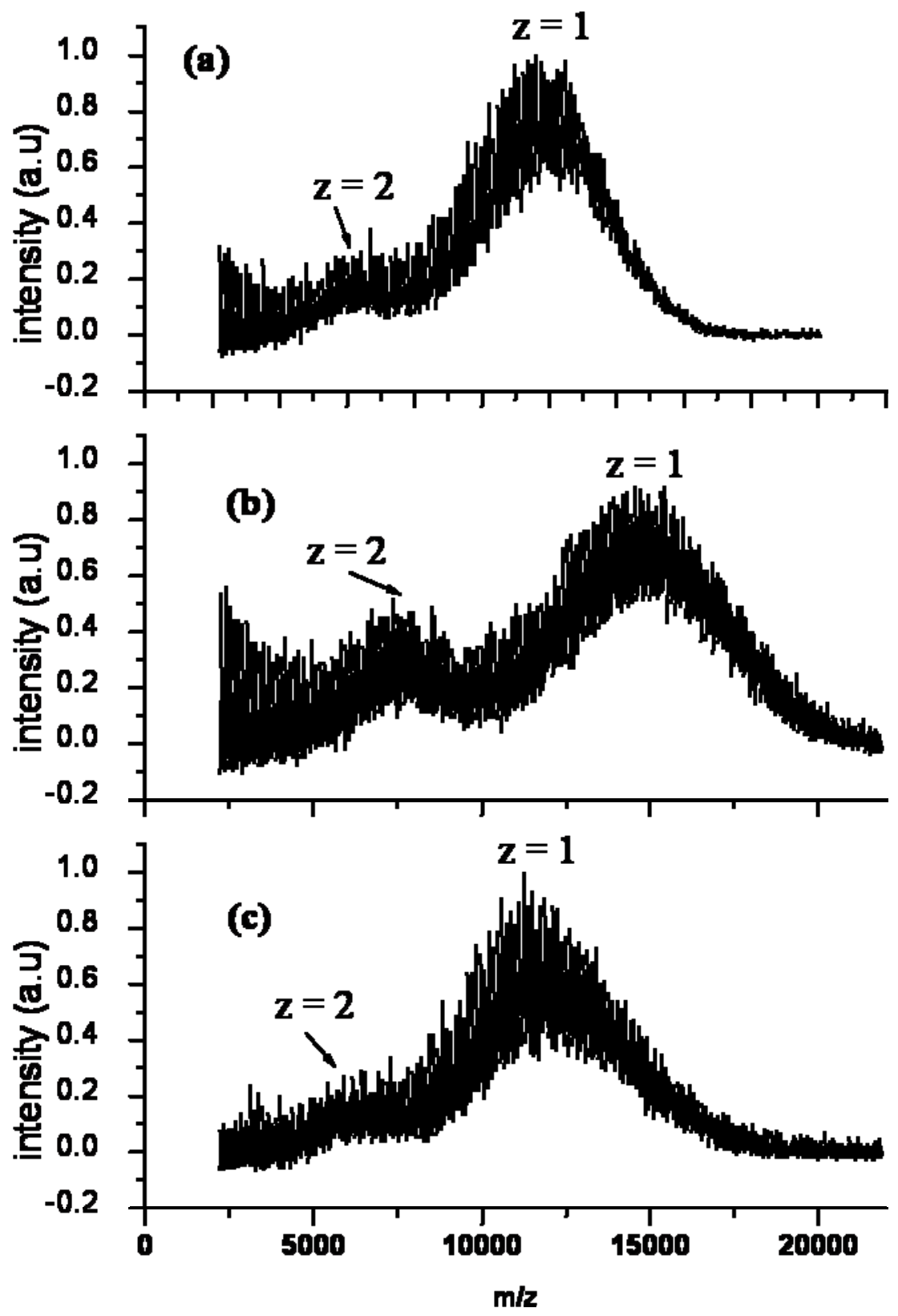

Figure S-6. MALDI-TOF mass spectra of the PDEAAm synthesized by $\mathrm{DPHLi} / \mathrm{Et}_{3} \mathrm{Al}$ in $\mathrm{THF}$ at $-78{ }^{\circ} \mathrm{C}$. (a) run $\mathrm{N}$, (b) run $\mathrm{P}$, and (c) run O. Experimental conditions: [DEAAm $]_{0}=$ $144-150 \mathrm{mmol} \cdot \mathrm{L}^{-1},[\mathrm{DPHLi}]_{0}=2.0-2.1 \mathrm{mmol} \cdot \mathrm{L}^{-1},\left[\mathrm{Et}_{3} \mathrm{Al}\right]_{0}=13.0-26.9 \mathrm{mmol} \cdot \mathrm{L}^{-1}$. 

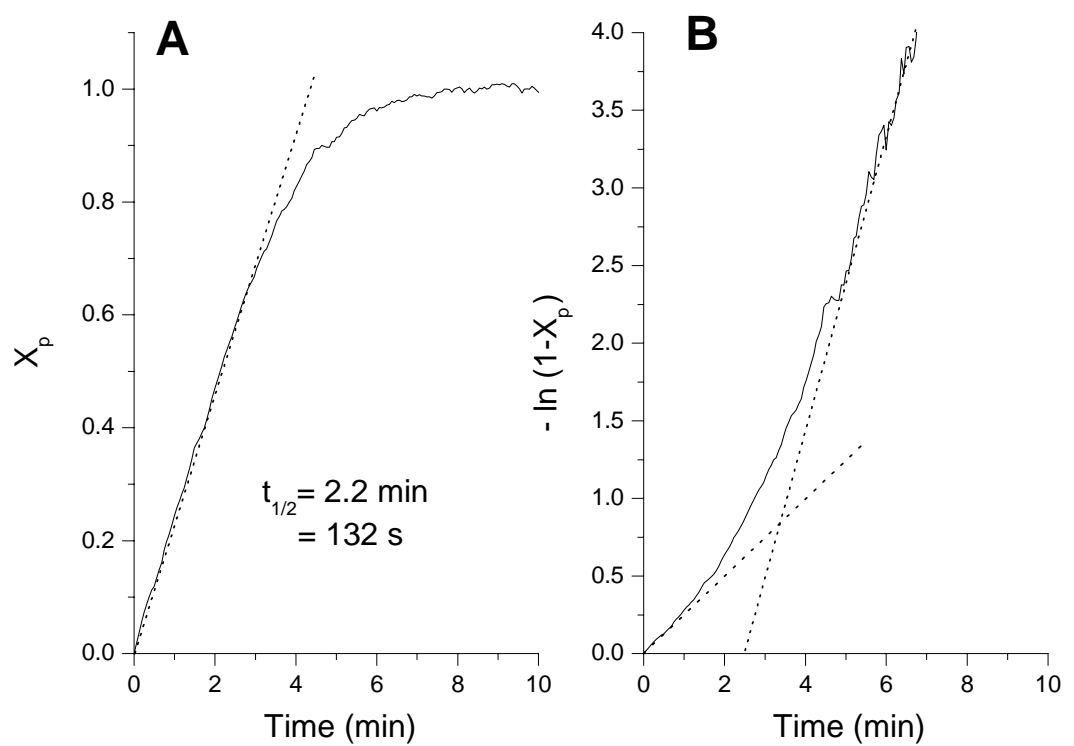

Figure S-7. (A) Linear and (B) first-order time-conversion plots for the polymerization of DEAAm initiated by PtBA-Li macroinitiator in THF at $-78{ }^{\circ} \mathrm{C}$ (run $\mathrm{G}$, see Table 1). Experimental conditions: $[\mathrm{DEAAm}]_{0}=94.0 \mathrm{mmol} \cdot \mathrm{L}^{-1},[\mathrm{P} t \mathrm{BA}-\mathrm{Li}]_{0}=1.80 \mathrm{mmol} \cdot \mathrm{L}^{-1},\left[\mathrm{Et}_{3} \mathrm{Al}\right]$ $=12.9 \mathrm{mmol} \cdot \mathrm{L}^{-1}$. 


\section{Calculation of the effect of coordination of $\mathrm{Et}_{3} \mathrm{Al}$ to monomer and chain ends on the kinetics of DEAAm polymerization}

In order to make the equations in this derivation more easily readable, we use abbreviations for the various concentrations given in Scheme S-1. Here, $\mathrm{X}$ denotes the adduct $\mathrm{Et}_{3} \mathrm{Al} \cdot \mathrm{THF}$, $P_{n}$ and $P_{n}{ }^{\prime}$ stand for an active and a deactivated $\left(\mathrm{Et}_{3} \mathrm{Al}\right.$ adduct) polymer chain, respectively, with $n$ monomer units, $M_{f}$ and $M_{a}$ are free and activated $\left(\mathrm{Et}_{3} \mathrm{Al}\right.$ adduct) monomer, respectively.

Scheme S-1

\begin{tabular}{|c|c|c|}
\hline Reaction & Equilibrium constants & Modified constants \\
\hline $\mathrm{X}+\mathrm{P}_{\mathrm{n}} \stackrel{K_{C E}}{\longleftarrow} \mathrm{P}_{\mathrm{n}}^{\prime}+\mathrm{THF}$ & $\mathrm{K}_{\mathrm{CE}}=\frac{P^{\prime} \cdot \mathrm{THF}}{X \cdot P}$ & $\mathrm{~K}_{1}=\frac{\mathrm{K}_{\mathrm{CE}}}{\mathrm{THF}}=\frac{P^{\prime}}{X \cdot P}$ \\
$($ Scheme 1b) & $\mathrm{K}_{\mathrm{M}}=\frac{M_{a} \cdot \mathrm{THF}}{X \cdot M_{f}}$ & $\mathrm{~K}=\frac{\mathrm{K}_{\mathrm{M}}}{\mathrm{THF}}=\frac{M_{a}}{X \cdot M_{f}}$ \\
\hline $\mathrm{X}+M_{\mathrm{f}} \stackrel{K_{M}}{\longleftarrow} \mathrm{M}_{\mathrm{a}}+\mathrm{THF}$ & & \\
$($ Scheme 1c) & & \\
\hline
\end{tabular}

For the various reagents the following mass balances are valid:

$$
\begin{aligned}
& A l_{0}=A l+X+P^{\prime}+M_{a} \\
& M_{f}+M_{a}=M \equiv M_{0}(1-x) \\
& I_{0}=P+P^{\prime}
\end{aligned}
$$

$A l_{0}, M_{0}$ and $I_{0}$ are the initial concentrations of $\mathrm{Et}_{3} \mathrm{Al}$, monomer and initiator, $A l$ and $X$ stand for free and THF-coordinated $\mathrm{Et}_{3} \mathrm{Al}$, respectively, and $x$ is the monomer conversion. Because of extremely exothermic reaction of $\mathrm{Et}_{3} \mathrm{Al}$ with $\mathrm{THF}\left(\Delta \mathrm{E}=-54 \mathrm{~kJ} \cdot \mathrm{mol}^{-1}\right.$, see Scheme 1a) the fraction of free $\mathrm{Et}_{3} \mathrm{Al}$ is extremely low and will be neglected.

By using the equilibrium constants and eqs (2) and (3) one can express $P^{\prime}$ and $M_{a}$ via the concentration of $\mathrm{Et}_{3} \mathrm{Al} \cdot \mathrm{THF}, X$, and introduce the fractions of activated monomer, $\alpha_{M}$, and of deactivated chain ends, $\alpha$ ': 


$$
\begin{aligned}
& M_{a}=M \frac{K X}{1+K X} \equiv \alpha_{M} M \\
& P^{\prime}=I_{0} \frac{K_{1} X}{1+K_{1} X} \equiv \alpha^{\prime} I_{0}
\end{aligned}
$$

Substituting these expressions into eq (S.1), one obtains the equation for $X$ :

$$
A l_{0}=X+I_{0} \frac{K_{1} X}{1+K_{1} X}+M \frac{K X}{1+K X}
$$

Equation (S.5) is a cubic equation with respect to $X$ and it was solved numerically for arbitrary values of concentrations $A l_{0}, M_{0}$, and $I_{0}$ and equilibrium constants $K_{1}$ and $K$. However, since most experiments were made under the condition $A l_{0}>>I_{0}$ (at least, $A l_{0} / I_{0}>10$ ) it is possible to neglect the second term in eq (S.5). Then, instead of a cubic equation one obtains the approximated quadratic equation for $X$

$$
A l_{0}=X+M \frac{K X}{1+K X}
$$

The solution of this equation is

$$
X=\frac{1}{2}\left\{\sqrt{\left(M+A l_{0}+K^{-1}\right)^{2}-4 M A l_{0}}-\left(M-A l_{0}+K^{-1}\right)\right\}
$$

Thus, for the fraction of activated monomer,

$$
\alpha_{M}=M_{a} / M=\frac{K X}{K X+1} \text {, }
$$

one obtains eq (4) of the main text independently of the initiator

$$
\alpha_{M}=\frac{1}{2}\left\{1+\frac{A l_{0}+K^{-1}}{M}-\sqrt{\left(1+\frac{A l_{0}+K^{-1}}{M}\right)^{2}-4 \frac{A l_{0}}{M}}\right\}
$$

Substituting (S.6) into eq. (S.4b) one obtains the expression for the fraction of coordinated chain ends, $\mathrm{P}^{\prime}$

$$
\alpha^{\prime}=\frac{\sqrt{\left(M+A l_{0}+K^{-1}\right)^{2}-4 M A l_{0}}-\left(M-A l_{0}+K^{-1}\right)}{\sqrt{\left(M+A l_{0}+K^{-1}\right)^{2}-4 M A l_{0}}-\left(M-A l_{0}+K^{-1}\right)+2 / K_{1}}
$$

Expressions (S.7) and (S.8) are valid always except for very high conversions when the concentration of monomer becomes close to the concentration of initiator. In that case the cubic equation for $X$ should be solved.

Assuming that the reactivity of coordinated centers, $P^{\prime}$, is much lower that that of $P$, the polymerization rate may be expressed as 


$$
R_{p}=\left(k_{p} M_{f}+k_{p}^{\prime} M_{a}\right) P=M I_{0}\left[k_{p}\left(1-\alpha_{M}\right)+k_{p}^{\prime} \alpha_{M}\right]\left(1-\alpha^{\prime}\right)
$$

Hence, the observed rate constant $k_{p, \exp }=k_{\text {app }} / P$ is

$$
k_{p, \exp }=\left[k_{p}\left(1-\alpha_{M}\right)+k_{p}^{\prime} \alpha_{M}\right]\left(1-\alpha^{\prime}\right)=k_{p}^{\prime} \frac{\lambda+K X}{1+K X} \cdot \frac{1}{1+K_{1} X}
$$

where $\lambda=k_{p} / k_{p}$ ' is the ratio of the propagation rate constants of free and activated monomer and $k_{\text {app }}$ is the slope of the first-order time-conversion plot.

In the course of the polymerization the concentration of THF-coordinated $\mathrm{Et}_{3} \mathrm{Al}, X$, increases and hence, the fraction of activated monomer, $\alpha_{M}$, also increases whereas the fraction of active chains, $P / I_{0}=1-\alpha^{\prime}$, decreases. Due to these two oppositely directed changes in $\alpha_{M}$ and (1- $\left.\alpha^{\prime}\right)$ the resulting behavior of the observed rate constant as a function of initial monomer concentration may be different depending on the relationship between $K$ and $K_{l}$. For example, for not very high $K_{l}$, i.e. when the fraction of active chain ends, $P$, is not very low, the polymerization rate decreases with increasing initial monomer concentration $M_{0}$. On the opposite, for high $K_{l}$ the observed rate constant, $k_{p, \exp }$, is the higher the higher the ratio $M_{0} / A l_{0}$. For some relationship between rate constants the dependence of $k_{p, \exp }$ on $M_{0}$ may even go through a maximum, however, this effect is not very pronounced. Also, if the reactivity of free monomer is not extremely low in comparison with that of activated monomer, the dependence of $k_{\text {app }}$ on conversion will be not very drastic.

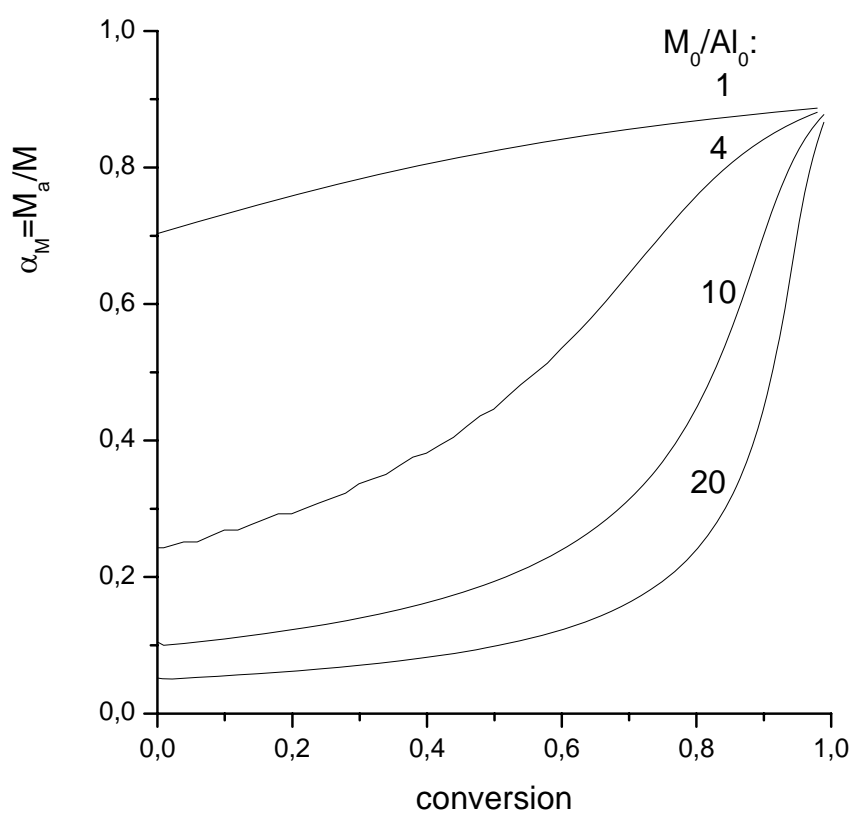

Figure S-8: Dependence of the fraction of activated monomer on conversion for different initial monomer concentrations. $k_{p}{ }^{\prime}=500 \mathrm{~L} \cdot \mathrm{mol}^{-1} \cdot \mathrm{s}^{-1}, k_{p}=0, A l_{0}=10^{-2}, I_{0}=10^{-3} \mathrm{~mol} \cdot \mathrm{L}^{-1}$, $K_{M}=10^{4} \mathrm{~L} \cdot \mathrm{mol}^{-1}$ 


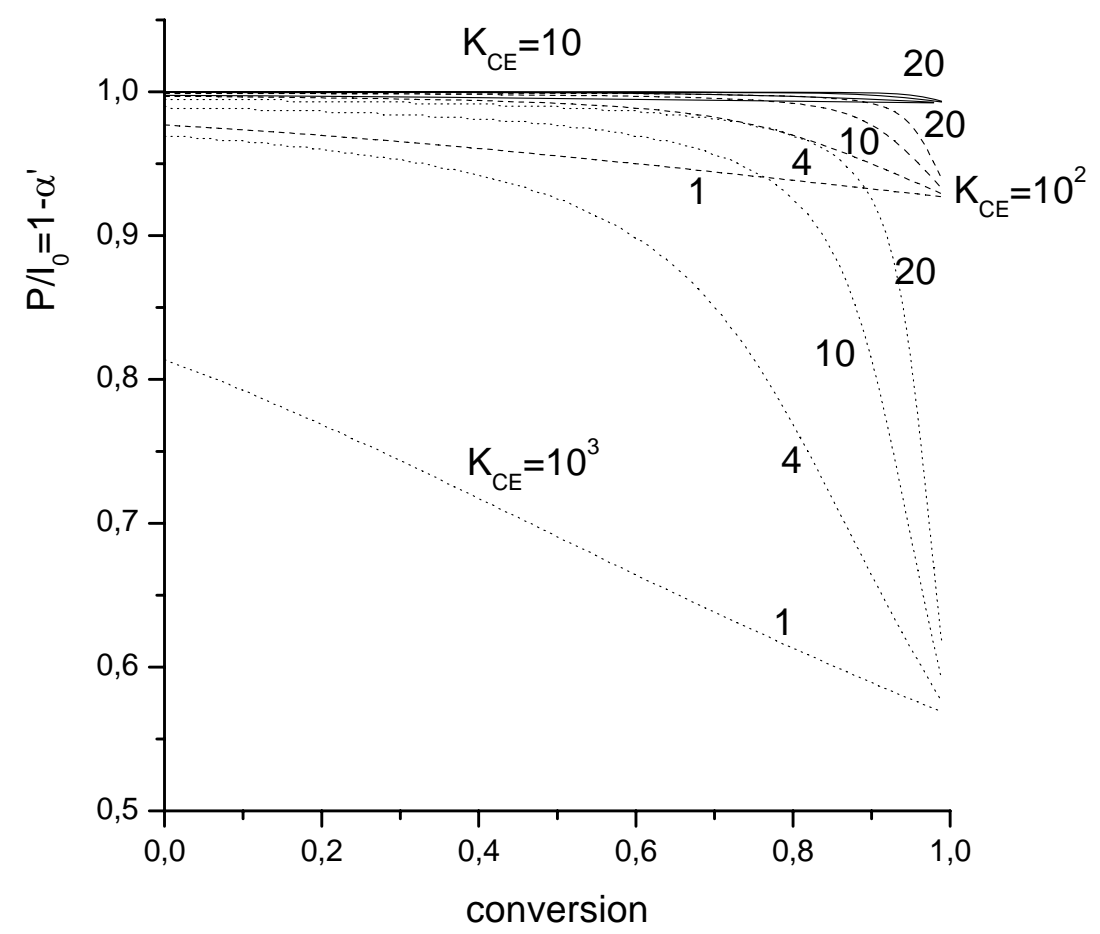

Figure S-9: Dependence of the fraction of active chain ends on conversion for different initial monomer concentrations and different $\mathrm{K}_{\mathrm{CE}} \cdot k_{p}{ }^{\prime}=500 \mathrm{~L} \cdot \mathrm{mol}^{-1} \cdot \mathrm{s}^{-1}, k_{p}=0, A l_{0}=10^{-2}$, $I_{0}=10^{-3} \mathrm{~mol} \cdot \mathrm{L}^{-1}, K_{M}=10^{4} \mathrm{~L} \cdot \mathrm{mol}^{-1}$

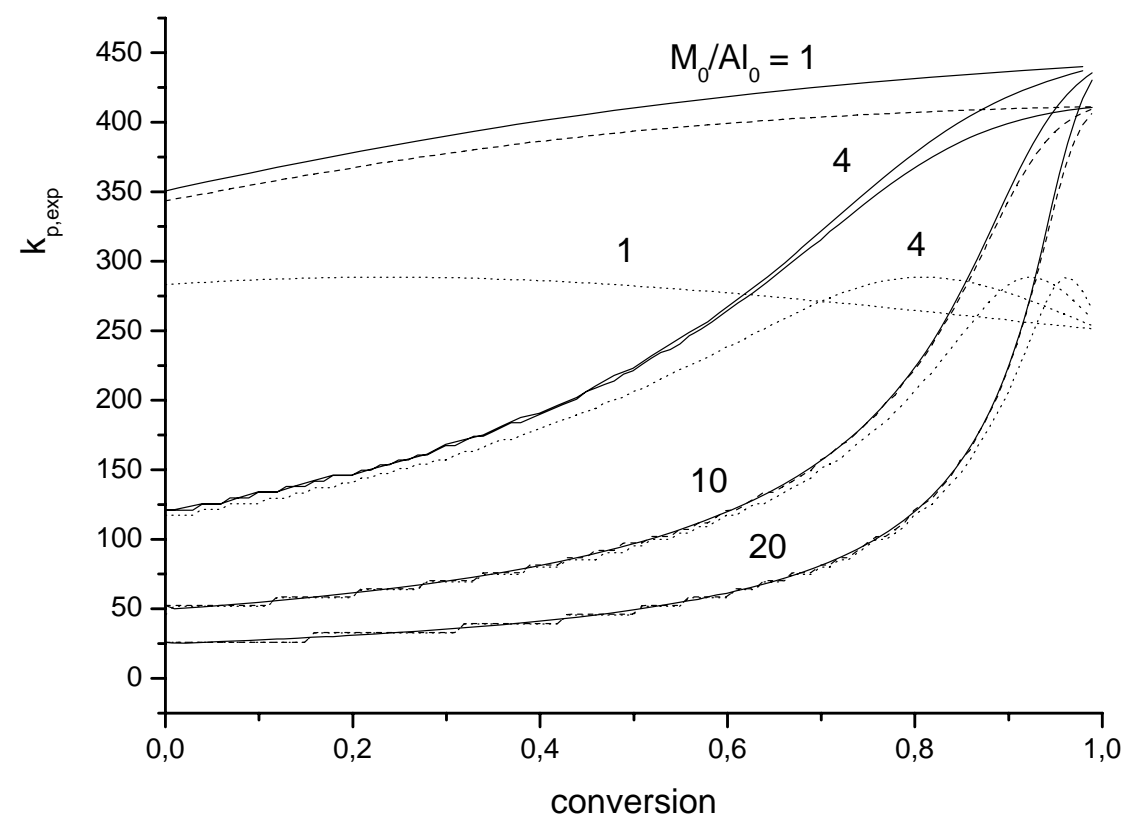

Figure S-10: Dependence of the observed rate constant on conversion for different initial concentration of monomer and different $\mathrm{K}_{\mathrm{CE}} \cdot\left[\mathrm{K}_{\mathrm{CE}} \cdot\left(\mathrm{mol} \cdot \mathrm{L}^{-1}\right)=10\right.$ (solid), $10^{2}$ (dash) and $10^{3}$ (dot) ]. $k_{p}{ }^{\prime}=500 \mathrm{~L} \cdot \mathrm{mol}^{-1} \cdot \mathrm{s}^{-1}, k_{p}=0, A l_{0}=10^{-2}, I_{0}=10^{-3} \mathrm{~mol} \cdot \mathrm{L}^{-1}, K_{M}=10^{4} \mathrm{~L} \cdot \mathrm{mol}^{-1}$. Numbers in the figure denote the $M_{0} / A l_{0}$ ratio. 
It follows from eqs (S.8) and (S.6) that the observed rate constant, $k_{p, \exp }$, can have an extremum as a function of aluminium concentration $A l_{0}$. The extreme (maximum) value of $k_{p, \exp }$ may be determined from the condition that the derivative of $k_{p, \exp }$ over $A l_{0}$ is equal to zero.

$$
\frac{d k_{p, \exp }}{d A l_{0}}=\frac{d k_{p, \exp }}{d X} \cdot \frac{d X}{d A l_{0}}=0
$$

As follows from eq (S.5), $d X / d A l_{0}$ is always $>0$. This means that maximum $k_{a p p}$ is reached when $d k_{p, \exp } / d X=0$. This condition is satisfied at

$$
X=\frac{\sqrt{\lambda^{2}+(1-\lambda) \cdot K / K_{1}-\lambda}-\lambda}{K}
$$

If $\lambda<<1$ one obtains from eq (S.10) that $k_{p, \exp }$ is maximum at

$$
X=\left(K K_{1}\right)^{-1 / 2}
$$

The concentration of aluminium at the point of maximum $k_{p, \exp }$ should be calculated from eq (S.5). The same is valid for the extremal dependence of $k_{\text {app }}$ on $M$, because

$$
\frac{d k_{p, \exp }}{d M}=\frac{d k_{p, \exp }}{d X} \cdot \frac{d X}{d M}
$$

and $d X / d M$ is always $<0$ (that is, $d X / d x=-d X / d\left(M / M_{0}\right)>0$ ). Hence, the maximum of $k_{p, \exp }$ is reached at $X$ determined from expressions (S.10).

Independently of the initial concentration of monomer, the final (at full monomer conversion) values of $\alpha_{\mathrm{M}}, \alpha^{\prime}$, and $k_{p, \exp }$ are defined only by the concentration of $\mathrm{Et}_{3} \mathrm{Al}, A l_{0}$, and the equilibrium constants. As follows from eq. (S.5), for $x \rightarrow 1$ the concentration of coordinated $\mathrm{Et}_{3} \mathrm{Al}$ is defined from equation

$$
A l_{0}=X+I_{0} \frac{K_{1} X}{K_{1} X+1} \approx X
$$

because $I_{0}<<A l_{0}$. Consequently, the final parameters are

$$
\begin{aligned}
& \alpha_{M} \approx \frac{K A l_{0}}{K A l_{0}+1} \\
& \alpha^{\prime} \approx \frac{K_{1} A l_{0}}{K_{1} A l_{0}+1} \\
& k_{p, \exp } \approx \frac{k_{p}+k_{p}^{\prime} K A l_{0}}{K A l_{0}+1} \cdot \frac{1}{K_{1} A l_{0}+1}
\end{aligned}
$$

